\title{
FACTORS THAT HINDER THE UTILISATION OF THE EMPLOYEE ASSISTANCE PROGRAMME IN THE DEPARTMENT OF LABOUR
}

\section{Florinda Taute, Kelly Manzini}

\section{INTRODUCTION}

In 1999 the Department of Public Service and Administration developed and implemented an Employee Assistance Programme (EAP) within the public service. This reaffirmed the government's commitment to intensify the programme to fight, inter alia, HIV and AIDS, and to deal with the traumas of everyday life, experiences of discrimination, cultural alienation and stress. A change in the programme focus has clearly occurred, to a certain extent, in response to the major transformation in South African governmental and non-governmental organisations. This change occurred as a result of the introduction of worker-related regulations such as the Basic Conditions of Employment Act 75 of 1997, the Labour Relations Act 66 of 1995, the Employment Equity Act 58 of 1998 and the Unfair Discrimination Act 4 of 2000, and made it necessary for the employer to investigate, assess and assist employees with problems relating to substance abuse or incapacity. These acts formed a solid basis for implementing the EAP.

The Department of Labour (DOL) responded promptly to the implementation of the EAP in 2001, yet the programme remains under-utilised and is seen both by management and employees of the Department as a social responsibility programme rather than a sound business strategy.

The existence of a written policy and its broad distribution, adequate staffing levels and provision of training for supervisors all predict higher levels of programme utilisation (Weiss, 2003:61). A study by Willbanks (1999:1) found that the following variables were constantly related to referral to the EAP: degree of management support for the EAP; gender of supervisors; gender of subordinates; the existence of a supervisor network; the occupational category of the employees supervised; social distance between supervisor and troubled employee; the supervisor's attitude; and knowledge about EAP.

Apart from factors relating to implementation of the programme, supervisory training and levels of staff awareness and issues of gender are inherent in EAP utilisation. "If employers want to retain trained, valuable employees, they must understand the relationship between gender and disasters or events and design programmes for the entire workforce" (Phillips, 2005:25). According to Phillips (2005:25), women and men do not experience events in the same way and this challenges employers to design programmes that meet the needs of both genders. According to the researchers, the dynamics of gender in relation to programme utilisation extends to include other factors of preference in consultation. The Department should also cater for diversity in ethnicity, race, religion and language to ensure complete accessibility of services to employees.

\section{EAP AT THE DEPARTMENT OF LABOUR (DOL)}

EAPs have been established for a variety of reasons, from developing alternative ways of managing poor performance with an emphasis on programme cost effectiveness, to giving expression to the concept of internal social responsibility (Harfer cited in Maiden, 1992:105). The business impact of EAP is often perceived as a secondary factor in motivating for an EAP. Alker and McHugh (2000:4) concur, as they argue that the primary reasons for the introduction of EAP tend to fall more into the area of humanistic concerns. According to Ndlala (2004), the 
DOL offers an EAP to help employees with their personal problems and, as a custodian and an enforcement agent of the majority of labour legislation in South Africa, strives to ensure that all its employees can avail themselves of effective EAP services.

The DOL, through its affiliation with the International Labour Organisation (ILO), adopted and implemented the principle of "Decent Work" (ILO, 2001:4). The goal of "Decent Work" is, according to the ILO (2001:4), to "connect people with their hopes to obtain productive work in conditions of freedom, equity, security and human dignity". It is both a personal goal for individuals and a development goal for countries - work for all people everywhere. Work is a means of sustaining life and of meeting basic needs. It is through the implementation of the EAP that the DOL demonstrates its commitment to promote the health and productivity of the employees. According to Kganyago (2004), the EAP practitioner at the DOL, despite efforts to promote "decent work", improve productivity and employee wellness, the DOL has still experienced an escalation in cases of misconduct relating to substance abuse, fraud and workplace violence and bullying, whilst referral to EAP - either voluntary or mandatory remains low.

\section{MARKETING THE EAP}

According to EAPA-SA (2005:21), EAPs will ensure the availability and use of promotional materials and educational activities, which encourage the use of the programme by supervisors, managers, worker representatives, peers, employees and family members. The goal of this standard is to ensure that the EAP is highly visible and that it is presented in a positive light to encourage members of the organisation to utilise the programme services fully.

It is imperative that an EAP identifies its goals for the overall marketing campaign and its objectives for any specific marketing or promotional activity. Oher (1999:92) mentions that the key to the successful internal marketing plan of an EAP is rooted not only in the knowledge of where the programme currently is, but where the organisation wants it to go. The author continues that the goals and objectives of any EAP marketing campaign can be summarised in five primary areas:

- To increase employees' knowledge of the EAP and its services, activities and key components;

- To increase familiarity and comfort with the EAP's operations and to enhance the acceptance and use of the service by employees, managers, labour representatives and the organisation's leadership;

- To increase utilisation of the programme at all levels throughout the organisation;

- To enhance the integration of the EAP within the host or contract organisation, and to promote a feeling of ownership for the programme on the part of the organisation and its managers and employees; and

- To maintain the visibility of the EAP and its presence as a vital contributor to the organisation's productivity and efficiency, and to the well-being and general work life of the employees and managers.

Documentation reviews of previous marketing efforts utilised by the DOL since 2001, which included awareness workshops and pamphlets, indicated that most EA marketing services rendered were limited to information on the management of chronic illnesses or problems addressed through the EAP. The Department relies on supervisors to identify and refer troubled employees to the EA programmes. According to Kganyago (2004) at the DOL, supervisors 
have been trained in the early detection of problems and the correct referral procedures, but this has been ineffective since EAP utilisation rates remains low.

The researchers established that minimal emphasis was placed on the marketing of empowerment and educational programmes at the DOL, and this factor is critical in influencing both the perceptions of the value of the programme and the prevention of stigmatisation of users.

\section{SUPERVISORS AND THE EAP}

Supervisors are essential to the EAP, since they are the first to notice any decline or change in the work performance of an employee, and the early identification of problems is the key to the success of an EAP. First-line supervisors are the EAP's most significant link to the company's employees, since they are in a position both to refer troubled employees and to support those employees who voluntarily make use of the service.

Peters (1999:96) describes the supervisor's primary function as "to ensure employees are productive", and this is dependent on the supervisor's training, insight and referral. Supervisors who have insight into the functioning of the EAP and who believe in the benefits of the programme will access the services of the EAP and refer appropriately.

Romano (1995:50) claims "[supervisory] training is essential to maintaining the health and vitality of EAPs" and in ensuring that they refer appropriately. Dayoff (1999:629) agrees with this, stating that a highly effective EAP must "take time to train and consult supervisors, to develop trust and confidence in the EAP". This sentiment was also expressed by Cohen (1985:118) as far back as the mid-1980s: "training supports the notion that it is all right to ask for help and that no one is expected to have all the answers to all of the employees' problems ... and is an effective means of enhancing supervisory understanding and utilisation of the EAP".

The training of supervisory personnel in EAP procedures is essential if supervisors are to utilise the EAP appropriately. This will help to develop them into a key referral resource. Referrals are, in turn, the lifeblood of the EAP.

\section{CONFIDENTIALITY AND THE EAP PRACTITIONER}

Social workers, psychiatrists, psychologists, physicians and others no longer dispute that absolute trust is essential between client and helping professionals, if the treatment process is to be effective. Trust cannot be fully achieved unless all personal information shared during the counselling process is kept confidential. It is the responsibility of the EAP practitioner to discuss confidentiality with the employee during the initial contact, as it may be essential to share selected information. It is essential to always ensure that the employee signs the consent form with the EAP practitioner relating to the sharing and management of information (EAPASA, 2005:14).

There is widespread recognition of the need to keep certain information confidential. In the researchers' opinion, this recognition is usually hindered by the lack of acknowledgement of the obligation to maintain confidentiality. Consequently EAPA-SA (2005:14) standards on confidentiality state that a written policy shall include a clause on confidentiality consistent with professional standards and ethics.

\section{RESEARCH METHODOLOGY}

As the researchers intended to explore the factors hindering the utilisation of the EAP, it was appropriate to follow the quantitative approach in this applied research to establish a 
knowledge base (Fouché \& Delport, 2005:74). The researchers utilised a quantitativedescriptive design (Fouché \& De Vos, 2005:137). They explored the goal of the study by means of a questionnaire that was developed after the in-depth review of literature on EAP. The study was conducted amongst employees at the DOL in Gauteng North, Pretoria, South Africa. A combination of closed- and open-ended questions was used in the questionnaire. The questionnaire consisted of the following sections:

Section A: Demographic details;

Section B: Awareness of the EAP services;

Section C: Attitude towards the use of EAP;

Section D: Accessibility of EAP (Preferences);

Section E: Purpose of an EAP.

The researchers used probability sampling with stratified random sampling (Strydom, 2005a:200) to select a sample of 55 employees from the population of 1100 employees from the following sampling sub-groups: the Unemployment Insurance Fund (UIF); the Compensation Fund (CF); and Head Office from employees at the DOL in Gauteng North, Pretoria, South Africa. The sample included men and women of all age groups from all levels of employment in the organisation irrespective of past experience in utilising the EAP.

Ethical issues taken into consideration (using Strydom, 2005b:58-67 as a guiding framework) were the importance of obtaining informed consent from respondents, safeguarding the privacy and identity of respondents, maintaining confidentiality, exercising caution and delicacy to avoid emotional harm; this was done to ensure the competence of the researchers and ensure the findings of this study would be published.

\section{PRESENTATION OF DATA}

The main purpose of this study was to investigate factors that hinder the utilisation of the Employee Assistance Programme at the Department of Labour. The following conclusions and recommendations are presented according to the different sections investigated.

\section{SECTION A: DEMOGRAPHIC DETAILS}

Fifty percent of the respondents were in the age group 26-35 years. The language distribution indicated that an African language was the home language of $43 \%$ of the respondents. Seventynine percent of the respondents were female, which correlates with the demographics that more females than males were employed in the DOL, Pretoria. The majority (53\%) of the respondents were married. Eighty-seven percent $(87 \%)$ of the respondents had five to eight years of work experience at the DOL and this ensured that there had been enough time for most respondents to become exposed to the existence and utilisation of the EAP.

\section{SECTION B: AWARENESS OF THE EAP SERVICES}

Eighty-six percent $(86 \%)$ of the respondents knew about EAP. Not only were they aware of the existence of the EAP, but the majority of respondents (60\%) viewed EAP as a counselling service, while $15 \%$ viewed EAP as a disciplinary service. This may imply lack of knowledge about the service or lack of identification of the EAP with productivity (management tool). The frequency of responses that identified EAP with stress management (13\%), HIV testing (4\%) and financial assistance (8\%) was encouraging, since EAPs are used predominantly to focus on personal crises, such as marriage counselling and substance abuse. 
The majority of employees $(51 \%)$ were first informed of the EAP through marketing during orientation programmes, $17 \%$ through marketing via awareness workshops and posters, and $32 \%$ by word of mouth through colleagues. A high percentage $(90 \%)$ of the respondents understood the EAP as a programme that could be utilised by all staff. There was a misconception amongst 5\% of the respondents that the EAP was only available for supervisors or senior managers. The statistics above suggested that most staff members were aware of the existence of the EAP service, which is contrary to the argument by the in-house practitioner at the DOL.

\section{Conclusions}

- The majority of respondents know and are aware of the services of the EAP.

- The EAP is viewed predominantly as a counselling service and this may impose limitations on the service.

- There is an association of the EAP with the disciplinary process, which suggests that staff would not trust the programme as it is viewed as a management tool.

- The orientation programme is proving to be the most effective means of marketing the service. This, however, has limitations because it only targets newly appointed staff.

- The encouraging factor is that the EAP is perceived as a service that is available for all staff to utilise and, most importantly, staff members expressed the need for management to continue providing the service.

\section{Recommendations}

- The DOL should begin to place considerable emphasis on the wellness component of EAP services. This can be achieved by developing and communicating a structured wellness programme with an educational/preventative approach.

- The marketing strategies aimed at promoting the EAP should not be combined with other promotional activities, until such time that EAP has established an identity of its own.

- There should be more interactive and personal approaches to marketing in the form of small-group educational workshops.

- Target different levels of staff to address the availability of EAP to all staff members.

\section{SECTION C: ATTITUDE TOWARDS THE USE OF EAP}

Only $14 \%$ of respondents have received EAP counselling which indicates that the EAP at the DOL is under-utilised; compare this with Simelane (2007:12), who indicates that $80 \%$ of utilisation of EAP is through self-referrals. Of the $14 \%, 83 \%$ of the respondents voluntarily sought EAP intervention. This may indicate failure on the part of supervisors to identify and refer employees needing EAP interventions.

Sixty-seven percent $(67 \%)$ of the respondents who utilised the EAP felt that the programme was beneficial and said they would use the programme again. The $33 \%$ who indicated that they would not use the service again cited problems relating to uncertainty about confidentiality and the limited privacy attached to the progress reports that are prepared for supervisors. EAPA-SA (2005:14) declares that the EAP's credibility depends on the maintenance of confidentiality and protecting the privacy of the employee.

The EAP is viewed as lending a helping hand to assist troubled employees by $61 \%$ of the respondents, whereas $37 \%$ view EAP as a programme that enhances productivity, whilst $2 \%$ 
viewed EAP as a programme that stigmatised employees. The main deduction was that $98 \%$ of respondents had positive perceptions about EAP.

\section{Conclusions}

- The majority of staff who have consulted the EAP are mostly self-referrals who find benefits in the service and are prepared to consult the programme again.

- A feeling of confidence about the privacy of the EAP exists and the service will be recommended to colleagues and family.

- There is concern about the professional management of the programme because of the possibility of access to feedback reports by supervisors.

- The EAP is perceived as a helping hand to troubled employees and thus most respondents are prepared to consult the programme when the need arises.

- Stigma is found to be the single most important factor discouraging employees from seeking help.

\section{Recommendations}

- A dedicated initiative directed towards the provision of supervisory training is essential.

- Policy provisions that identify with the EAP, catering for the wellness of employees and their families, need to be emphasised during programme promotions.

- The DOL should develop a reporting template for supervisors that is limited to demographic or statistical information, and should formulate recommendations to enable the supervisor to fulfil a supportive role.

- A key strategy in dealing with stigma is through the provisions of the policy that protects staff and discourages discrimination.

\section{SECTION D: ACCESSIBILITY OF EAP (PREFERENCES)}

The location of the EAP at Head Office influences $63 \%$ of the respondents in their decision to access the programme. According to Harper (2000:319), various EAP models suggest the location of the EAP influences accessibility. However, 59\% of the respondents would still have preferred the EAP to be managed within the workplace and not by visiting consultants (7\%).

The majority of respondents $(80 \%)$ would have preferred to access a counselling service that would be in their language. It is thus very important to offer programmes that reflect the languages of the employees, mainly for easier expression, better communication and offering a help in establishing rapport. The majority of the respondents $(69 \%)$ did not mind the age of the EAP counsellor and $85 \%$ did not mind the gender of the EAP counsellor.

Ninety percent $(90 \%)$ of the respondents indicated that the most preferred form of counselling was face-to-face. Email counselling received $8 \%$ responses, whilst telephone counselling was the least preferred, with only $2 \%$ of the respondents choosing this option. The preferred personal counselling poses challenges for the DOL, since it only employs two full-time practitioners based at Head Office in Pretoria. 


\section{Conclusions}

- Onsite counselling services are preferred, manned by workplace consultants.

- Counselling in the respondent's language is preferred.

- The age and gender of a counsellor were not found to be factors that influence accessibility of the service.

- The most preferred form of counselling is face-to-face counselling.

\section{Recommendations}

- Since the EAP is centralised at Head Office and not accessible to all employees, it is recommended that the EAP be coupled with the employment of additional practitioners at provincial office levels.

\section{SECTION E: PURPOSE OF AN EAP}

Nearly all respondents (99\%) saw a benefit in utilising the EAP - benefit to the employer, employee and the Union. The main purpose of an EAP, according to $29 \%$ of the respondents, was to promote employee wellness, followed by an increase in productivity (26\%) reducing health risks $(26 \%)$, while $15 \%$ indicated resolving management problems. The lowest ranked purpose of an EAP, according to $2 \%$ of the respondents, was to dismiss staff.

The $68 \%$ of respondents indicating that management supported the EAP suggests an encouraging trend in successful programme implementation as management support is a key ingredient of a successful programme (EAPA-SA, 2005:8).

\section{Conclusions}

- Most employees saw benefits in utilising the EAP.

- Management and supervisors supported the programme.

\section{Recommendations}

- Return on investment for managers and supervisors needs to be presented, in which the rand and cents savings of the EAP can be shown.

\section{SUMMARY}

This study was aimed at identifying factors that hinder the utilisation of the EAP at the Department of Labour through a scientific study in which data collection, presentation and analysis were scientifically conducted.

The goals and objectives of the study were reached, since the study managed to describe the theoretical framework of factors preventing the utilisation of the EAP in the workplace. The study successfully explored and scientifically described the factors hindering the utilisation of EAP services at the DOL. Furthermore, the study presented recommendations for management consideration regarding strategies to improve utilisation of the Employee Assistance Programme at the Department of Labour.

This work can be concluded with the description by Gornick and Blair (2005) of the trends in, inter alia, social work that lead to the system approach and the stimulation of awareness of the commonalities of employee assistance. These authors describe how an understanding of family systems transformed the practice of social work in the 1970s. "By extension, family systems theory has been applied to the organisational family. Work groups in many ways replicate 
family systems" (2005:5), and the application of systems theory in groups has become an integral part of proactive programmes in the EAP.

\section{REFERENCES}

ALKER, L. \& McHUGH, D. 2000. Human resources maintenance. Journal of Managerial Psychology, 15:4.

BASIC CONDITIONS OF EMPLOYMENT ACT, 1997 (Act 75 of 1997). Government Gazette, No. 15999. Pretoria: Government Printers.

COHEN, M. 1985. EAP training to integrate performance appraisals, evaluation systems, and problem-solving skills. In: KLARREICH, S.H., FRANCEK, J.L. \& MOORE. C.E. The human resources handbook: principles and practices of employee assistance programmes. New York: Praeger.

DAYOFF, M. 1999. The seven practices of highly effective EAPs: advice for programme and personal survival. EAP Digest, March/April:28-29.

EAPA-SA. 2005. Standards for employee assistance programmes in South Africa. Johannesburg.

EMPLOYMENT EQUITY ACT, 1988 (Act 55 of 1998). Government Gazette, No. 19370. Pretoria: Government Printers.

FOUCHÉ, C.B. \& DE VOS, A.S. 2005. Quantitative research designs. In: DE VOS, A.S. (ed), STRYDOM, H., FOUCHÉ, C.B. \& DELPORT, C.S.L. Research at grassroots: for the social sciences and human service professions $\left(3^{\text {rd }} \mathrm{ed}\right)$. Pretoria: Van Schaik Publishers.

FOUCHÉ, C.B. \& DELPORT, C.S.L. 2005. Introduction to the research process. In: DE VOS, A.S. (ed), STRYDOM, H., FOUCHÉ, C.B. \& DELPORT, C.S.L. Research at grassroots: for the social sciences and human service professions $\left(3^{\text {rd }}\right.$ ed). Pretoria: Van Schaik Publishers.

GORNICK, M.E. \& BLAIR, B.R. 2005. Employee assistance, work-life effectiveness, and health and productivity: A conceptual framework for integration. In: ATTRIDGE, M., HERLIHY, P.A. \& MAIDEN, R.P. 2005. The integration of employee assistance, work/life, and wellness services. New York: Haworth Press, Inc.

HARPER, T.D. 2000. Employee assistance programme and professional developments. In: MASI, D.A. (ed) International employee assistance anthology ( $2^{\text {nd }}$ ed). Washington: Dallen Inc.

ILO (INTERNATIONAL LABOUR ORGANISATION). 2001. Reducing the decent work deficit. Geneva: ILO Publications.

KGANYAGO, F.M. 2004. Personal interview. EAP practitioner at Department of Labour, 19 March. Pretoria.

LABOUR RELATIONS ACT, 1995 (Act 66 of 1995). Government Gazette, No. 16861. Pretoria: Government Printers.

MAIDEN, R.M. 1992. First world EAP serving third world clients: A U.S. perspective of the South African experience. In: MAIDEN, R.M. (ed) Employee assistance programmes in South Africa. USA: The Haworth Press.

NDLALA, A.Z. 2004. Personal interview. Executive Manager HRM/EAP at Department of Labour. 23 March 2004. Pretoria. 
OHER, J.M. 1999. The employee assistance handbook. New York: John Wiley \& Sons, Inc.

PETERS, H.J. 1999. A value driven approach to the operations of a South African EAP vendor. In: MAIDEN, R.M. Employee assistance programmes in the new South Africa. New York: Haworth Press, Inc.

PHILLIPS, B.D. 2005. Gender and disasters. Journal of Employee Assistance, 35(2):25-27. ROMANO, M.E. 1995. Redefining supervisory, shop steward training. EAP Digest, January/ February:50.

SIMELANE, S.N. 2007. Perceptions of supervisors regarding their referral role within the Employee Assistance Programme. Pretoria: University of Pretoria. (MSD Mini Dissertation)

STRYDOM, H. 2005a. Sampling and sampling methods. In: DE VOS, A.S. (ed), STRYDOM, H., FOUCHÉ, C.B. \& DELPORT, C.S.L. Research at grassroots. For the social sciences and human service professions $\left(3^{\text {rd }}\right.$ ed $)$. Pretoria: Van Schaik Publishers.

STRYDOM, H. 2005b. Ethical aspects of research in the social sciences and human services profession. In: DE VOS, A.S. (ed), STRYDOM, H., FOUCHÉ, C.B \& DELPORT, C.S.L. Research at grassroots. For the social sciences and human service professions $\left(3^{\text {rd }}\right.$ ed). Pretoria: J.L van Schaik Publishers.

UNFAIR DISCRIMINATION ACT, 2000 (Act 4 of 2000). Government Gazette, No. 19422. Pretoria. Government Printers.

WEISS, R.M. 2003. Effects of program characteristics on EAP utilization. Employee Assistance Quarterly, 18(3):61.

WILLBANKS, K-D. 1999. The role of supervisory referral in employee assistance programs. Employee Assistance Quarterly, 15(2):13-28.

Dr Florinda Taute, Mr Kelly Manzini, postgraduate student, Department of Social Work and Criminology, University of Pretoria, Pretoria, South Africa. 